\title{
Episodic influx of mantle-derived magma precedes eruptions at Cumbre Vieja volcano, La Palma, Canary Islands
}

\author{
S. TRAMONTANO ${ }^{1,2}$, M-A. LONGPRÉ ${ }^{2,1}$
}

${ }^{1}$ Earth and Environmental Sciences, The Graduate Center, City University of New York, New York, NY, USA (*stramontano@qc.cuny.edu)

${ }^{2}$ School of Earth and Environmental Sciences, Queens

College, City University of New York, Flushing, NY, USA

In this study, we exploit Cumbre Vieja volcano, on La Palma, Canary Islands, as a natural laboratory to explore the nature of eruption run-up processes and the potential relationship between repose period and rejuvenation timescales at hot-spot volcanoes. Cumbre Vieja erupted six times since 1585, with repose periods ranging from 22 to 237 years, each time producing very similar basanite-tephrite tephra and lava (45-49 wt\% $\mathrm{SiO}_{2}$ ). Previous work has shown that pre-eruptive magma storage and crystallization takes place at upper mantle depth beneath La Palma [1]. We present EPMA transects and X-ray maps of zoned olivine and clinopyroxene crystals for all six historic eruptions supported by diffusion chronometry and thermodynamic models. Olivine and clinopyroxene crystals display similar systematic zoning patterns across all eruptions. "Shoulder-type" zoning is most common; $84 \%$ of analyzed olivine crystals have a near-identical core composition (Fo81.4 \pm 1.4 ), a reversely zoned inner rim (Fo83.5 \pm 0.8$)$ and a steeply, normally zoned outer rim. Clinopyroxene crystals display anhedral, low-Mg\# (67.7 \pm 6.3) cores with patchy textures and abundant apatite inclusions. These cores are encased by multiple euhedral zones of higher $\mathrm{Mg} \#(76.6 \pm 4.4)$ and $\mathrm{Cr}$ content. We propose that episodic influx of primitive basanite melt from depth invades evolved crystal mushes in the uppermost mantle, leading to entrainment of lower- $\mathrm{Mg} \#$ crystal cores and subsequent crystallization of overgrowth rims richer in $\mathrm{Mg}$, $\mathrm{Ni}$ and $\mathrm{Cr}$, with multiple injection events taking place between days to months before eruption. Steep normal zoning at the outer rim of crystals is interpreted to reflect rapid crystallization upon final magma ascent, as supported by our MELTS models. These results indicate that primitive melt recharge is a critical reactivation mechanism at Cumbre Vieja. Variation in the timing of injections (alongside subtle differences in zoning) across all six eruptions may suggest a relationship between magma supply rate from the mantle and breaks in eruptive activity at the Canary Island hot-spot.

[1] Klügel et al. (2005), EPSL 